\title{
Emergency guidelines for two abandoned mines in Piani dei Resinelli area (Lecco)
}

\author{
M. Papini, L. Longoni \& K. Dell’Orto \\ Politecnico di Milano, Italy
}

\begin{abstract}
The reconversion of abandoned mines for touristic aims tentatively began some years ago: now it has gained great acknowledgement from the public and specialists who are interested in the historic, scientific and cultural aspects of mines. Due to this increased presence of tourists it is necessary to ensure safety inside mines. In the last years the issue of safety in underground works aroused great attention in Italian, European and Extra-European state laws after the occurrence of serious lethal accidents inside road galleries, extractive mines and caves. However, these laws only apply to mines still in use, with have different problems than those occurring in abandoned mining sites. Old mines, now used for touristic purposes, are visited by people that don't know anything about problems that can occur in underground environments and don't perceive risk situations: they can display unpredictable behaviour and in critical conditions it is very difficult to keep the situation under control.

As a result, we developed these Emergency Guidelines (based on two mines) in order to create a model and originate general directives to be followed by other mines, as happens with other events in the Civil Protection field. First of all we defined risk scenarios and then traced the necessity of mobilization of operative structures. In addition, mines have been mapped with a GIS, including in the geo referenced map all the information about the mine that we thought to be useful to provide faster and more effective intervention in case of an emergency.
\end{abstract}

Keywords: abandoned mines, safety, GIS, risk scenarios. 


\section{Introduction}

Safety inside mines is a point of fundamental importance, because of the greater probability of the occurrence of natural hazards in underground fields with respect to surface ones. In recent years the issue of safety in underground works has gained great attention in Italian, European and Extra-European state laws after the occurrence of serious mortal accidents inside road galleries, extractive mines and caves. But these laws apply only to operational mines, with different problems from those occurring in abandoned mining areas. In this way, safety in mines used for touristic aims has a priority to protect people who want adventurous, cultural or scientific experiences.

Until now the development of this new kind of tourism has continued without any law about safety and matters of Civil Protection, so in case of an accident there's no model to be followed to guarantee visitor safety. This emergency guideline, based on two mines, proposes to be a model for other similar visitor attractions, both in Italy and other countries. However every place has got specific features and some particulars may not been considered by this work in order to present it as a general guideline. In this way, the risk scenarios and intervention models presented below are made considering a particular mine but they can be used in a lot of other cases similar to the one presented.

\section{The case study}

Mining area containing Anna and Cavallo mines is located in Piani dei Resinelli, a locality of Abbadia Lariana (Lecco, Italy). In the past this area has been of great importance for the extraction of argentiferous galena, so a lot of mines have been opened to extract this mineral. It is possible to access to the Anna mine from rifugio SEL (Società Escursionistica Lecchese), at $1270 \mathrm{~m}$ a.m.s.l., and following a short track along Val Calolden, reaching the principal gateway at $1220 \mathrm{~m}$ a.m.s.l. (see the map in fig. 1). Access to Cavallo mine is possible starting from the 12th hairpin turn (road sign) long the road from Ballabio to Piani dei Resinelli. The area is reachable from Lecco city following the direction to Valsassina and then following signs to Piani dei Resinelli (from Lecco about 30-40 minutes by car).

\section{Aid stations in the area are:}

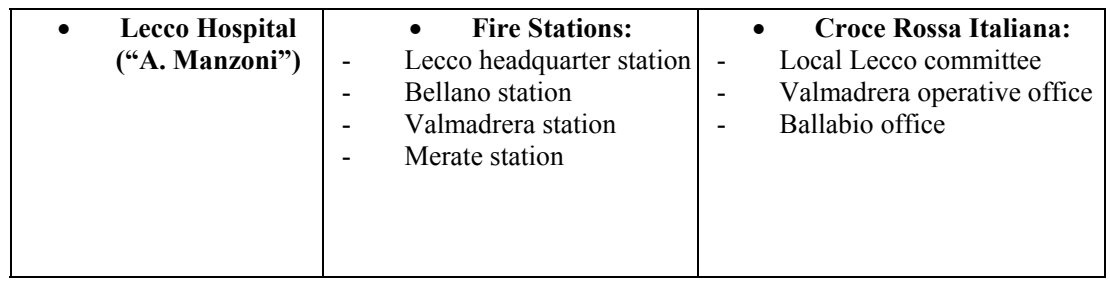

To see the position of rescue stations in Lecco, see the map below (fig. 2): 


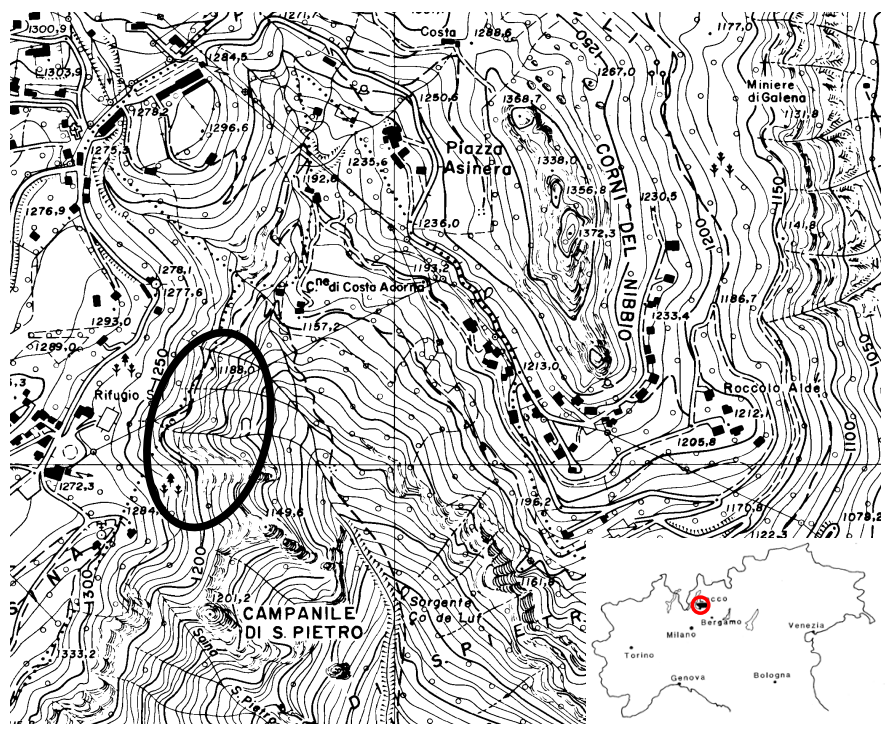

Figure 1: $\quad$ Map with position of Piani dei Resinelli Mine.

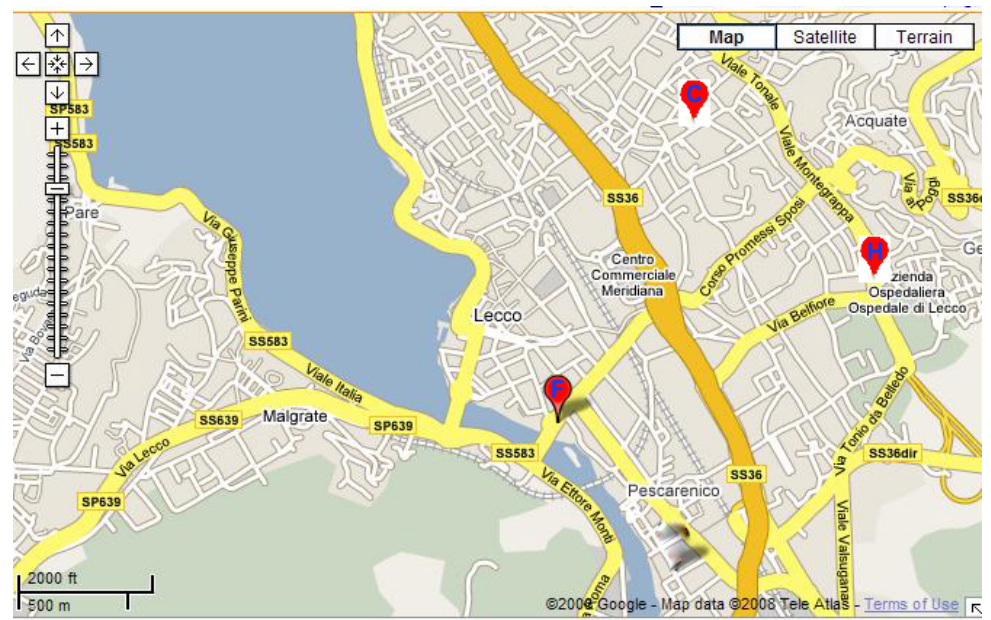

Figure 2: $\quad$ Position of rescue stations in Lecco: Fire Station (F), Hospital (H) and Croce Rossa (C) (map taken by Google Map, C2008 Google).

\subsection{Map of mines}

The Anna mine map (the most visited mine in the area) has been made with the use of a terrestrial laser scanner, which generated a high-precision map. The Cavallo mine map (with a very low presence of tourists) instead has been made using analogical instruments (total station). 
Over the centuries, different methods of extraction in the mines have created an irregular and complex plan; extraction by hand, dynamite and air hammer (Anna mine only) have all left their mark. In addition, mineral veins have been followed in a systematic way, sometimes leaving pillar to sustain the vault, so there's not a real order in the shape of caves; however, most of these tunnels follow the SW-NE direction in Anna mine and SE-NW direction in Cavallo mine. Some of the waste products have been used to build up stonewalls along most parts of the trace, and used to fill a part of the old cavities.

Ribasso Umberto is a "carreggio" gallery at $1220 \mathrm{~m}$ a.m.s.l. linked to the Anna mine by a vertical gallery, and follows the WSW-ENE direction. The visit starts from the ticket office, on the square under the Piani dei Resinelli skyscraper. Then, a trail that passes through a wood into Calolden valley brings to the main access of the Anna mine, while another track brings the visitor to the $12^{\text {th }}$ hairpin turn and from it to the main access of Cavallo mine. The whole track followed by tourists has been mapped with different colours to define three different routes suggested by guides, depending upon the level of experience of the visitors: route number one has been made for children, number two for adults and number three only for experts. It must be said that in the case of Cavallo mine only the expert route exists (the mine is characterized by extreme and wild conditions).

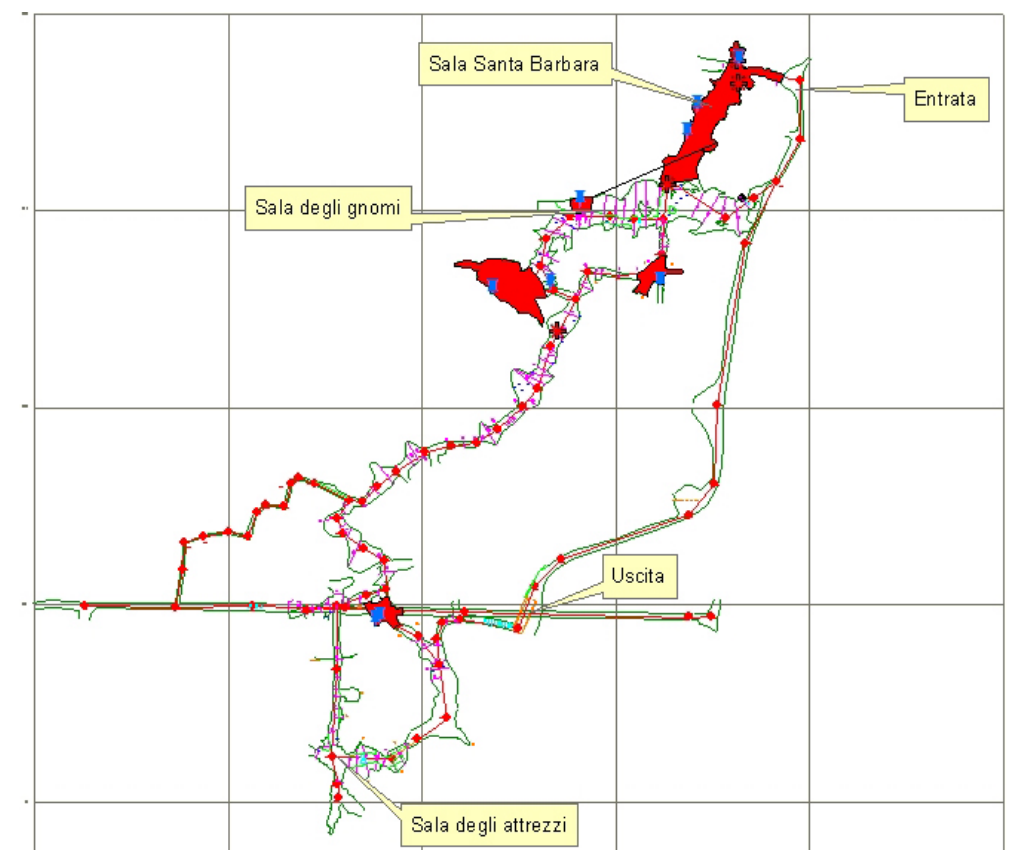

Figure 3: $\quad$ Map of Anna mine, with position of monitored areas (red) and crackmeters (blue). 
During the visit, tourists pass through a route that, in general, lasts for 50 minutes, on a track that sometimes is slippery, often with a low vault (it is very easy to hit the head on the vault). For expert visitors it is also possible to visit the lower part of the Anna mine, Ribasso Umberto, which is accessible via a very steep stair. All tunnels are illuminated by a series of lights and emergency lights, although helmets with headlamps are also worn by tourists in order to have complete visibility; especially in Cavallo mine where the lights and emergency lights are mostly out of duty. From the ticket office a phone line runs to the Anna mine. There are two phones, one positioned at the beginning and one at the end of the mine track. All the tracks either in Anna and Cavallo mine are provided with two fire extinguishers and two first-aid kits.

In order to make the mine safer some tracks have been shored up with tree trunks. Principal cracks and faults are monitored with a system of crackmeters either one dimensional or three dimensional. The position of the emergency exits, gathering areas and exit routes, position of phones, fire extinguishers, first aid kits and position of monitored areas, crackmeters and unstable blocks are described in the GIS maps (see an example in figs 3 and 4).

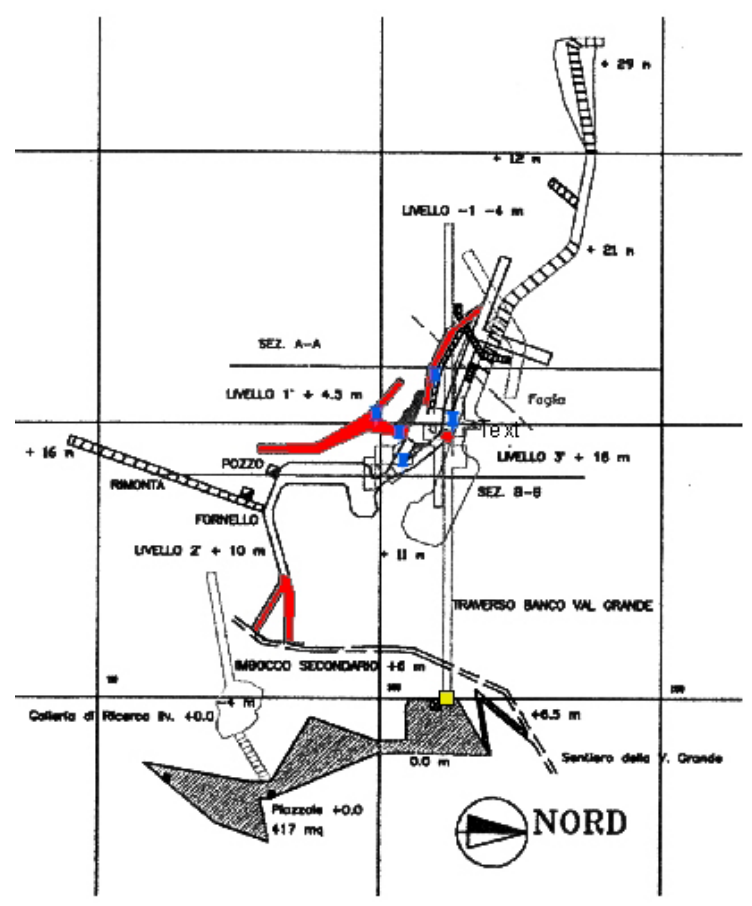

Figure 4: $\quad$ Map of Cavallo mine, with position of monitored areas (red) and crackmeters (blue). 


\section{Characterization of risks and risk scenarios}

Risk events have been divided in two categories: external risks and internal risks. External risks concern injuries occurred during the walk from the ticket office to the mine (for example caused by the presence of mud on the walk).

Internal risks concern:

- Injuries to tourists due to sliding, hit of the head on the vault, etc.

- Damage to electric wiring.

- Collapse of rock blocks of every size and in every point inside the mine (however, it is important to notice that little collapses are more difficult to forecast than big ones).

- Collapse of rock walls inside the mine.

Risk scenarios are intended to be events that can occur inside and outside the mine, due to human and/or natural reasons. In the examined mine we identified several scenarios, with different probabilities of occurring:

\section{Critical events outside the mine:}

Injuries:

- The tourist is able move.

- The tourist is not able to move.

2. Critical events inside the mine:

Injuries:

- The tourist is able to move.

- The tourist is not able to move.

Damage of electric wiring:

- Start of emergency lights system.

- Damage of emergency lights system (emergency lights system doesn't start).

Instability of the rock mass with collapses inside caves:

- The group is still united.

- The group is still united, with injured able to move.

- The group is still united, with injured not able to move.

- The group is divided in two parts, without injured.

- The group is divided in two parts, with injured able to move.

- The group is divided in two parts, with injured not able to move.

The occurrence of these events depends on several parameters, so it is difficult to determine. However, common sense suggests that the most probable event is an injury along the trail before reaching the mine: after rainfalls the ground becomes very slippery and it is easy for tourists to fall.

\section{Intervention model}

The intervention model is an important point (perhaps the most important of the emergency guideline), and it offers a model on how to face emergencies, rescue people and restore normal state of life. First of all a figure is needed to be defined: the director of rescue operations, with the duty to work against the effects of critical events. In general, the Mayor of the city interested by the 
critical event, as the local Authority of Civil Protection activates emergency measures: as a support to the Mayor there is another figure, the Town Operative Representative (TOR), which has to manage staff, volunteers and emergency areas. The Mayor also establishes a Local Crisis Unity (LCU), made-up of people experienced in the field of emergency management.

In case of accidents inside the mine the settlement of LCU is not always done, it depends on the size of the event: it is assembled only when an event of significant dimensions occurs, like a collapse of vaults or any kind of relevant instability of the rock mass. In this case LCU is composed of:

- Abbadia Lariana Mayor

- TOR

- Comunità Montana del Lario Orientale (mine owner) President

- Mines safety representative (to be nominated by the mine Administrator)

- Technicians (to help in decisional, executive, administrative and technical phases)

- $\quad$ Local Police Office Commander

- Area Civil Protection Group manager.

This structure will be joined by other components (chosen by the Mayor): a Police officer, Firemen Chief, mine guides (supposing they know mines).

LCU components (available $24 \mathrm{hrs}$ ) will meet in an office as soon as possible in order to support the Mayor until the end of the emergency situation. For minor entity emergency scenarios, mine guides will elect between themselves a chief guide, as the Emergency Representative, to manage the emergency situation. Guides will also have to fill in a form (fig. 5) where they will register data about tourists in the mine.

It is important to mention the Emergency Coordinator, who is an expert of the mine, who has got the task to stay in the ticket office and to activate procedures that are necessary to pass out emergency.

\begin{tabular}{|c|c|}
\hline \multicolumn{2}{|c|}{ Society } \\
\hline Date: & $\begin{array}{cl}\text { Weather: } & \\
& \quad \text { Calm Weather } \\
& \square \quad \text { Changeable Weather } \\
& \quad \text { Rainy Weather }\end{array}$ \\
\hline 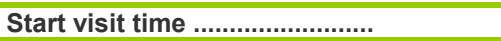 & 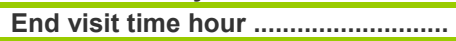 \\
\hline 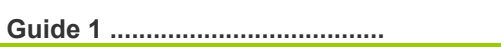 & 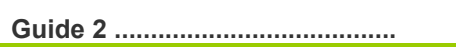 \\
\hline 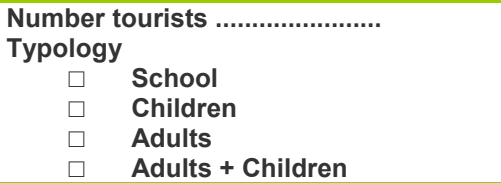 & 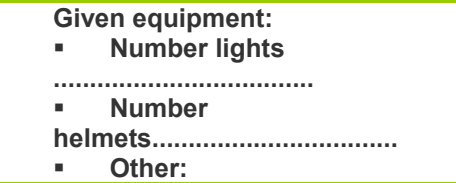 \\
\hline 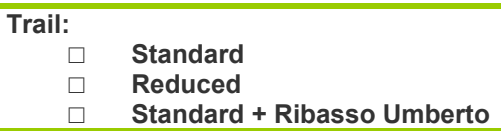 & Notes: \\
\hline
\end{tabular}

Figure 5: $\quad$ Form to be filled in for every visit to mines. 


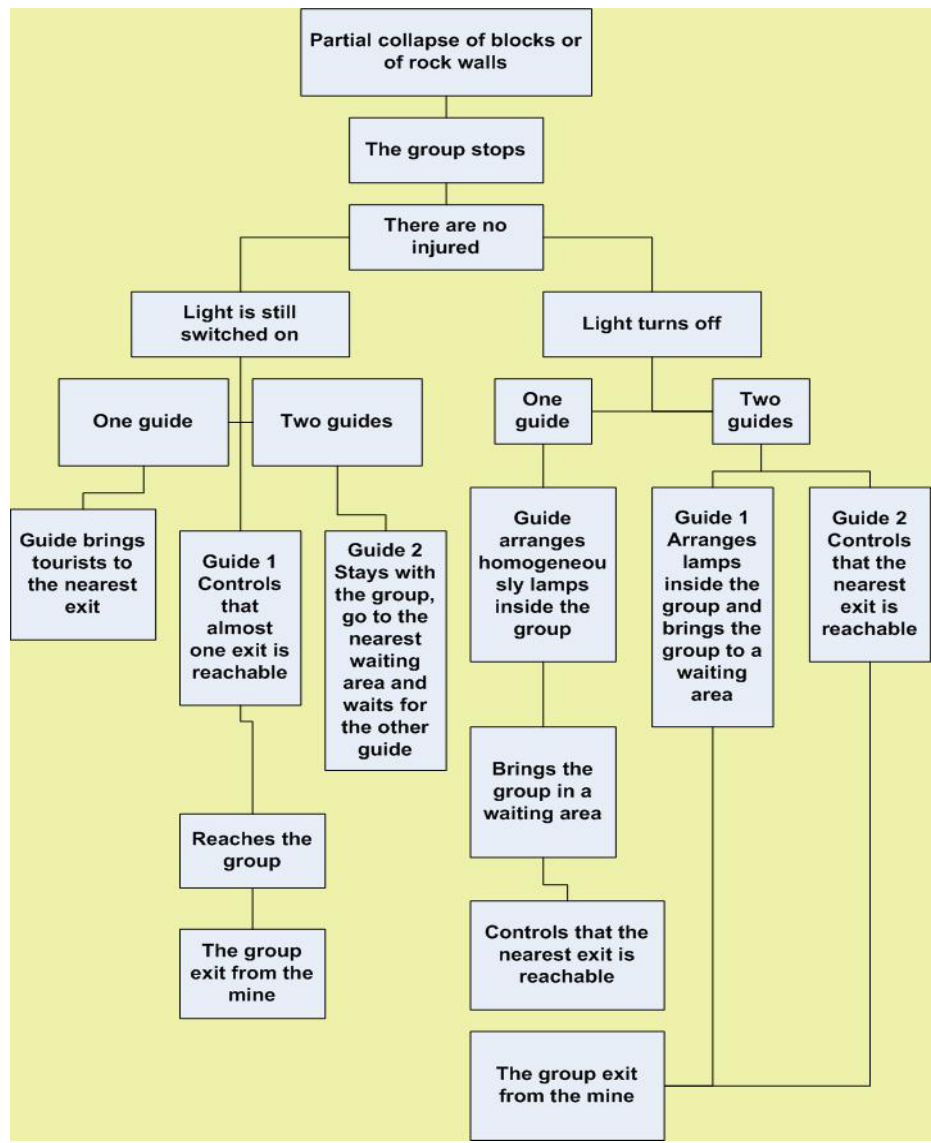

Figure 6: Scheme of an intervention model for a risk scenario (in this case, collapse of rock walls).

The Emergency Representative together with Emergency Coordinator and Safety Representative will activate emergency procedures and contact Civil Protection institutions (Firemen, Police, etc.).

Procedures to be followed are schemed with three steps:

1. Events tree

2. Actions tree

3. Intervention tree

However it is too difficult to singularly schematize these three trees, so we considered it to be better to make a scheme composed of a singular tree that includes all aspects together: events, actions and interventions (see example in fig. 6).

In order to describe the sequence of procedures to be followed for every considered scenario it is better to define "waiting areas" inside the mine (places where to bring tourist in case of an accident) and emergency exits. 
Waiting areas have to be safe and wide, in order to contain at least 30 people. Intervention practices must be divided following a sequence of codes:

1. Pre-alarm code.

2. Alarm code.

3. Emergency code.

As events that could happen inside the mine are difficult to forecast, it would be better to be always ready for the emergency code. However, if during the monitoring of crackmeters an operator detects a movement, safety representative activates the alarm code and the mine is closed until the cause of the movement has been detected and removed. The succession of the events is schematized in tree diagrams in order to give easy access to intervention modalities and a fast check of the guideline.

\section{Application of a Geographic Information System (GIS)}

A GIS (Geographic Information System) is a software instrument useful to acquire, store, extract, transform and visualize spatial data from the real world. This system allows for the production, management and analysis of spatial data linking every geographic element with one or more alpha numeric descriptions.

Using it for mapping mines is the best way to obtain a clear representation of the mine and of all points of the map considered to be interesting for the management of an emergency guideline: location of lights, emergency lights, emergency exits, emergency areas, phones, first aid kits, etc. Every point has to be provided with a description of its characteristics and with a link to its photo.

Maps for this guideline have been intended as something interactive, in order to allow everyone to quickly acquire information on the mine: fast data retrieval is fundamental in case of an emergency situation, where loss of time has never to be considered.

\section{Conclusions}

The aim of this guideline is to safeguard people visiting mines, analyzing all possible risk scenarios (and the probability of each one happening) in order to be able to manage every kind of accident that can occur during a visit. The only case that has not been considered is a fire inside the mine, as the probability of that happening is very low (the humidity inside mines is very high and wood used to sustain vaults is often wet).

In order to validate an emergency guideline system it is fundamental to execute a text exercise, to find possible bugs and to allow it to be updated with eventual new parts. So at least one exercise per year has to be done, simulating a case of accident to test how the system runs.

It is important to say that from the analysis of possible scenarios it resulted that for every visit the presence of at least two guides in the mine is necessary: in case of an emergency the first one would stay with tourists and the other would go out and look for help. In particular, the presence of two guides is highly 
108 Underground Spaces I

recommended for visits made after a long rainy period: the ground inside mines gets very slick and the probability of low entity collapses is high.

\section{References}

[1] Giussani Alberto, Relazione sul rilievo topografico delle miniere "Anna" e del "Ribasso Umberto" ai Piani dei Resinelli, Politecnico di Milano, 2006.

[2] Rodeghiero F., Jadoul F., Vailati G. e Venerandi I. (1986), Dati preliminari sulle mineralizzazioni a $\mathrm{Pb}-\mathrm{Zn}$ dell'area tra Mandello e Ballabio (Lombardia Centrale). Memorie della Società Geologica Italiana, 32: 133-150.

[3] Papini Monica et al., Caratterizzazione geomeccanica con metodi statistici e valutazione MRES del rischio geologico presso i cantieri della Miniera Anna e del Ribasso Umberto, Politecnico di Milano, 2006.

[4] Papini et al., Requisiti e linee generali per la realizzazione di un sistema di monitoraggio delle miniere dei Piani dei Resinelli, Politecnico di Milano, 2007. 